\title{
Simulation of ionospheric error on GPS signals due to changes in the direction of mobile station positions in differential GPS
}

\author{
Siti Sarah Nik Zulkifli , Mardina Abdullah, Mahamod Ismail \\ University Kebangsaan Malaysia, Department of Electrical, Electronic and Systems Engineering, Selangor, Malaysia
}

\author{
Article history \\ Received March 27, 2011; accepted August 15, 2011.
}

Subject classification:

Ionosphere, Ray-tracing, dGPS, Baseline.

\begin{abstract}
Ionospheric propagation delay is one of the major sources of error in global positioning system (GPS) precision. Therefore, accurate estimation of the ionospheric delay is required to correct GPS positional calculations. This study investigates the simulation of ionospheric propagation delays of GPS signals caused by changes in the direction of mobile station positions in differential GPS. A comparison was made between shortdistance $(\leq 10 \mathrm{~km})$ differential GPS ionospheric errors at rover stations and those at a single base station located at the University Kebangsaan Malaysia $\left(2^{\circ} 55^{\prime} \mathrm{N}, 101^{\circ} 46^{\prime} \mathrm{E}\right)$. In this simulation, four different baseline orientations were considered: North $\left(0^{\circ}\right)$, East $\left(90^{\circ}\right)$, South $\left(180^{\circ}\right)$ and West $\left(270^{\circ}\right)$ of the University Kebangsaan Malaysia GPS station. Without consideration of any irregularities, the ionospheric errors at the northern rover station were nearly symmetrical to those at the southern station, which is elevation dependent. Similarly, there were nearly symmetrical ionospheric errors for the following orientation pairs: East $\left(90^{\circ}\right)$ and West $\left(270^{\circ}\right)$; Northwest $\left(315^{\circ}\right)$ and Southeast $\left(135^{\circ}\right)$; and Northeast $\left(45^{\circ}\right)$ and Southwest $\left(225^{\circ}\right)$. To maximize the quality of GPS positioning, all ionospheric errors need be considered so that accurate corrections can be made and precision can be enhanced.
\end{abstract}

\section{Introduction}

Global positioning system (GPS) is currently one of the most useful satellite positioning technologies, due to its global availability and the high performance levels of the GPS signals. Nevertheless, GPS signals that propagate through the Earth ionosphere, which is about $60 \mathrm{~km}$ to $1,500 \mathrm{~km}$ above the Earth surface, will be affected by the free electrons in this medium. The signal that passes through this medium can be slowed down (as signal velocity is only constant in a vacuum), and can thereby cause an error in range measurements. As the ionosphere undergoes daily changes during the day-light hours, the ionospheric delay can be 3-fold to 4-fold greater during the day than the night, and thus these GPS signal delays can vary. The distribution of electrons in the ionosphere is thought to be the most important parameter that affects the propagation of radio waves and GPS applications [Iyiade 2006]. The ionospheric range error is proportional to the secant of the satellite zenith angle, a value that increases from 1 to about 3 as the satellite moves from the zenith to the horizon. Thus, the vertical range error can be three-or-more-times larger for observations at low elevations (i.e., from $5^{\circ}$ to $15^{\circ}$ ) than at higher elevations, due to the longer travel paths through the ionosphere.

The ionospheric delay of a GPS signal is related to the total electron content (TEC). The TEC describes the level of activity in the ionosphere, and it is quantified by counting the number of electrons between the satellite and the receiver in a vertical column with a cross-sectional area of $1.0 \mathrm{~m}^{2}$. It is measured in TEC units (TECU), where 1 TECU is equal to $10^{16}$ electrons $/ \mathrm{m}^{2}$ [Parkinson and Spilker 1996]. The TEC is strongly dependent on the elevation angle of the satellite (which is governed by the receiver-satellite geometry), because the signal path through the ionosphere is longer at lower elevations [Klobuchar 1987]. As the ionospheric delays are dispersive, they depend on the frequency of the signal. The densities of the free electrons change dynamically according to the time of day and the latitude of any given position.

The study of ionospheric determination in the improvement of precise navigation by GPS is a booming field of research. Nowadays, most of the real-time network correction considers the observation of the carrier phase and the pseudorange correction. GPS users can achieve centimeter-scale positioning accuracy using the carrierphase-based differential GPS technique, in which two or more geodetic-quality GPS receivers are deployed to correct for ionospheric effects [Abdullah et al. 2003, Choy et al. 2008]. The current differential GPS (DGPS) technique, which uses code positioning, also provides precise results in return, because the errors from the satellite and receiver are either removed in the short baseline, or reduced in the long baseline [Orús et al. 2003].

In DGPS, the effects of the ionosphere can be determined at the base station and subsequently used to correct the range 
measurement at a rover station. This technique can be applied to both general situations and to situations that rely on one or more base stations at well-known locations. Examples of DGPS real-time network correction for positioning services include the Ground-Based Augmentation System (GBAS) used in Australia for air navigation and for precise landing of a plane, and the U.S. Nationwide Differential Global Positioning System (NDGPS) for navigation systems. The residuals are computed by comparing the known and estimated satellite locations. The range errors are broadcast to the rover receivers, where the appropriate correction is applied [Kintner and Ledvina 2005]. This method is useful when the base receiver and the rover receiver have common error sources and when the ionospheric propagation error is the same at both receivers (i.e., both receivers observe the signal through the same ionosphere).

This study presents an analysis and simulation of the differences in ionosphere-induced GPS signal delays at four rover stations in differential GPS, dGPS (NB. a small ' $d$ ' is used here to differentiate from the abbreviation used for the currently available DGPS system) application. Relative to the base station, the rover stations were oriented to the North $\left(0^{\circ}\right)$, East $\left(90^{\circ}\right)$, South $\left(180^{\circ}\right)$ and West $\left(270^{\circ}\right)$. The ionospheric delays or advances were calculated based on the differences between the ray-path distance from the satellite to the receiver, which was determined using a ray-tracing program, and the expected distance for propagation over the line-ofsight (LOS), which was calculated assuming the velocity of light in a vacuum. In this study, ionospheric irregularities are not considered, as we used the data on an undisturbed day. The four different baseline orientations were studied to quantify the differences in ionospheric delays between the base and the rover paths. Most ionospheric models in practice do not consider higher order terms in the refractive index expansion, which means the geomagnetic field or path refraction is neglected, but these issues were accounted for in the modified Jones three-dimensional (3-D) ray-tracing program [Ioannides and Strangeways 2002].

\section{Calculation of the ionospheric delayed or advanced signal}

The range error caused by the Earth ionosphere can range from less than $1 \mathrm{~m}$ to as much as $100 \mathrm{~m}$, and this changes according to the time of day, solar activity, season, receiver location, viewing direction, and state of the Earth magnetic field. The result is that a particular phase of the carrier arrives earlier at the receiver than it would have if the signal had traveled from the satellite to the receiver in a vacuum [Davies 1990]. Additionally, a signal that modulates the carrier signal (i.e., the pseudorandom noise codes and navigation message) is delayed during propagation through the ionosphere. This delay of the modulating signal is known as the group delay, and its magnitude is believed to be identical to the magnitude of the phase advance. The ionospheric range error is proportional to the secant of the satellite zenith angle, a value that increases from 1 to about 3 as the satellite moves from the zenith to the horizon. Thus, the vertical range error can be three or more times larger for observations at low elevations (i.e., from $5^{\circ}$ to $15^{\circ}$ ) than at higher elevations, due to the longer travel paths through the ionosphere.

The ionospheric error for the delay or advance of a signal was extracted from the Appleton-Lassen equation [Abdullah et al. 2008] and used in the 3-D ray-tracing program. To determine the group and phase paths, the modified 3-D ray-tracing program was used, by consideration of the full-form refractive index both without and with the geomagnetic field at azimuth and elevation angles appropriate for the L1 and L2 GPS frequencies [Abdullah et al. 2007, Ya'acob et al. 2009, Abdullah et al. 2010]. Calculations were performed to investigate the ionospheric effects for both the carrier phase and the group paths. The ionospheric errors experienced by the GPS signal in the dGPS application can be determined at the base and the rover stations using the 3-D ray-tracing program. The signal delay or advance, $t d$, depends on the ray path distance from the satellite to the receiver $\left(P_{r}^{s}\right.$, as determined from ray tracing) and the true path length or the distance of the LOS (dLOS) at the velocity of light in a vacuum (for details, see Zulkifli et al. [2007]). The relationship is given in the form of Equation (1):

$$
t d=P_{r}^{s}-d L O S
$$

The differences in the delays between the two paths can subsequently be found by subtracting the signal delay at the rover station from the signal delay at the base station [Abdullah et al. 2003, 2007, 2009], as shown in the Equation (2):

$$
\Delta t d=t d_{b a s e}-t d_{\text {rover }}
$$

where $t d_{\text {base }}$ is the ionospheric delay at the base station, and $t d_{\text {rover }}$ is the ionospheric delay at the rover station.

\section{Methodology}

A modified 3-D Jones ray-tracing program was used to investigate the ionosphere-induced error in the GPS signals. The effectiveness of this method was reported previously by Zulkifli et al. [2009], Abdullah et al. [2009] and Ya'acob et al. [2009]. For the present study, the GPS station at University Kebangsaan Malaysia (UKM) $\left(2^{\circ} 55^{\prime} \mathrm{N}, 101^{\circ} 46^{\prime} \mathrm{E}\right)$ was chosen as the base station. The ionospheric profile taken for this analysis was on June 7, 2007, during a geomagnetic quiet day, which is defined as a day with no geomagnetic storm activity. In this simulation, ionospheric irregularities have not been taken into consideration; however, for studies on ionospheric irregularities and ionospheric gradients using ray-tracing, see Abdullah et al. [2007]. To get accurate results from the ray-tracing technique, the electron density model 
must have a continuous function as well as continuous first, second, third and higher order spatial derivations [Ioannides and Strangeways 2002]. An electron density model that adheres to these criteria can be proposed by producing an exponential layer. The exponential layer is a parabolic layer that has been shaped using the exponential function. An exponential function (as given in Equation 3) is used to fit a true profile generated from the NeQuick standard model [Leitinger and Radicella 2002] to produce a new modeled profile. The shape of the exponential layers is dependent on the exponent $a$, where the parabolic-shaped layers $(a=2)$ are in the range of $100-600 \mathrm{~km}$ in altitude:

$$
N_{e}=N_{m} \exp \left[-\left(\frac{h-h_{m}}{\sigma}\right)^{a}\right]
$$

where, $N_{m}$ is the maximum electron density of the exponential layer, $h$ is the height above the Earth surface, $h_{m}$ is the altitude of $N_{m}$, and $\sigma$ is the semi-thickness of the layer. The parameters for each layer are used as inputs to the 3-D ray-tracing program. Figure 1 shows the process of fitting the NeQuick ionospheric profile with 24 exponential layers to produce a new modeled profile. This process is important to get an ionospheric profile with continuous first-order spatial derivatives, as required in ray tracing. A processing flow diagram that briefly outlines this process is shown in Figure 2.

The ray-tracing program is used to determine the established ray paths from a particular satellite for both the base and the rover stations using additional inputs from the azimuthal direction and the baseline length between the base and the rover stations. This technique ascertains that the same satellite location is applied for both the base and the rover stations. The ray-tracing program has an embedded minimization function that alters the initial azimuth and elevation angles to find the GPS satellite altitude. This was done theoretically to study the effects of different propagations in the dGPS application. Ray tracing determines the actual path between the known transmitter and receiver locations, whether in space or on the ground, without making any approximations based on the ionosphere. A minimization termination tolerance of $10^{-4}$ was used for both angles [Strangeways 2000]. This method ensures that each ray begins at the exact position of the satellite. The main parameters to be fit were the variations in the ionospheric delay for various elevation angles. The ray path between the satellite and the receiver is assumed to be reversible, which means that it will always take the same path for a given elevation angle.

To determine the impact of ionospheric variation on the DGPS range, the location of the rover station must be specified. This can be accomplished by setting the azimuth angle and the required baseline length with respect to the base station. For this analysis, the rover station was located $10 \mathrm{~km}$ from the base station and was positioned due north of the GPS station at UKM. The rover was displaced to analyze the impacts

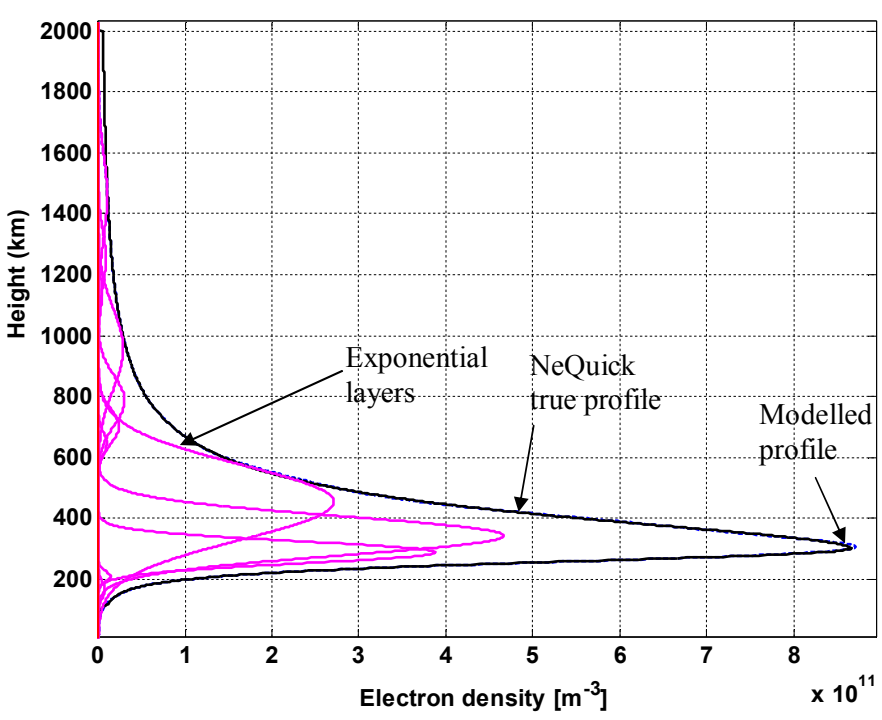

Figure 1. Fitting a NeQuick ionospheric profile with a number of exponential layers. Pink curves, exponential layers; black curve, the NeQuick true profile; blue layer, the modeled profile.

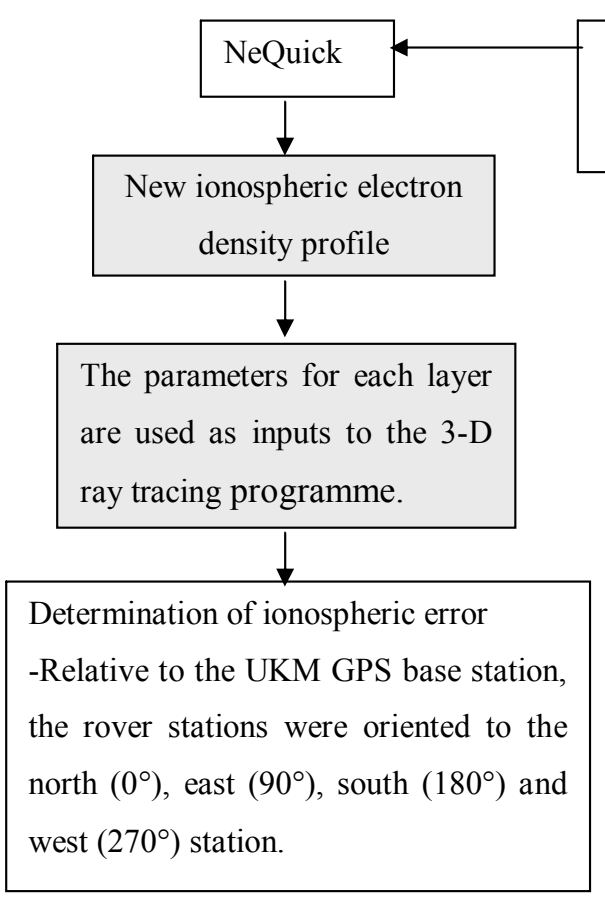

Figure 2. Flow diagram outlining the process of fitting the NeQuick ionospheric profile.

for four different directions: North (located at $3^{\circ} \mathrm{N}, 101^{\circ} 46^{\prime} \mathrm{E}$ ), East (located at $2^{\circ} 55^{\prime} \mathrm{N}, 101^{\circ} 51^{\prime} \mathrm{E}$ ), South (located at $2^{\circ} 49^{\prime} \mathrm{N}$, $101^{\circ} 46^{\prime} \mathrm{E}$ ), and West (located at $2^{\circ} 55^{\prime} \mathrm{N}, 101^{\circ} 40^{\prime} \mathrm{E}$ ).

For each direction, the azimuth angle was set to $30^{\circ}$, and 18 elevation angles ranging from $5^{\circ}$ to $89^{\circ}$ were investigated. The differences in the ionosphere-induced delay for the different orientations were then studied. Figure 3 shows the four ray-path directions and the geometric relationships between the base and the rover stations. In all of the analyses, the satellite orbit and receiver heights were assumed to be $20,200 \mathrm{~km}$, according to the GPS height. 


\section{Results and discussion}

The difference in the delay, $\Delta t d$, was evaluated for a $10-\mathrm{km}$ separation between the base station and the rovers. Four rover orientations were studied: due North, East, South and West. Figure 3 shows $\Delta t d$ as a function of the elevation angle. For the

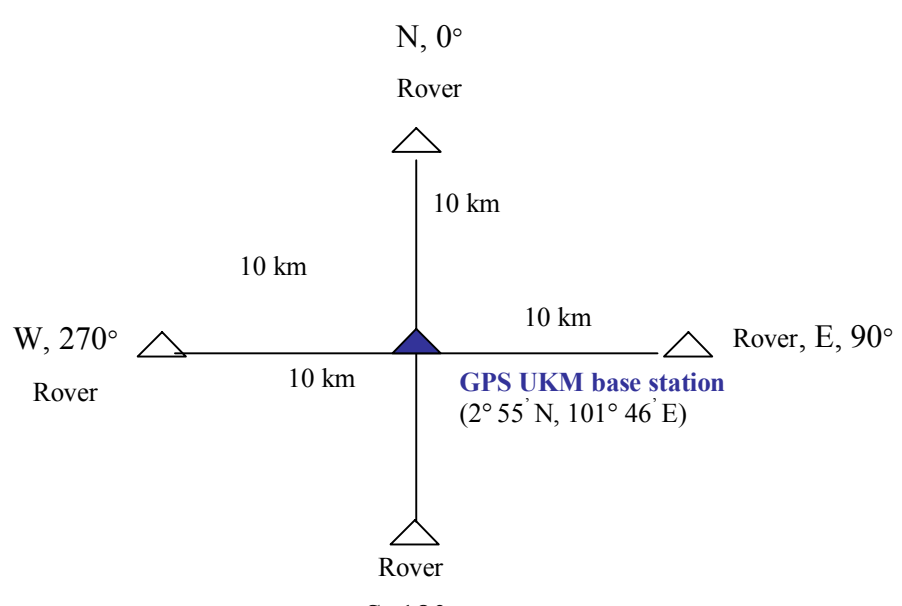

S, $180^{\circ}$

Figure 3. The ray path directions and the geometric relationships between the GPS base station at UKM and the rover stations.

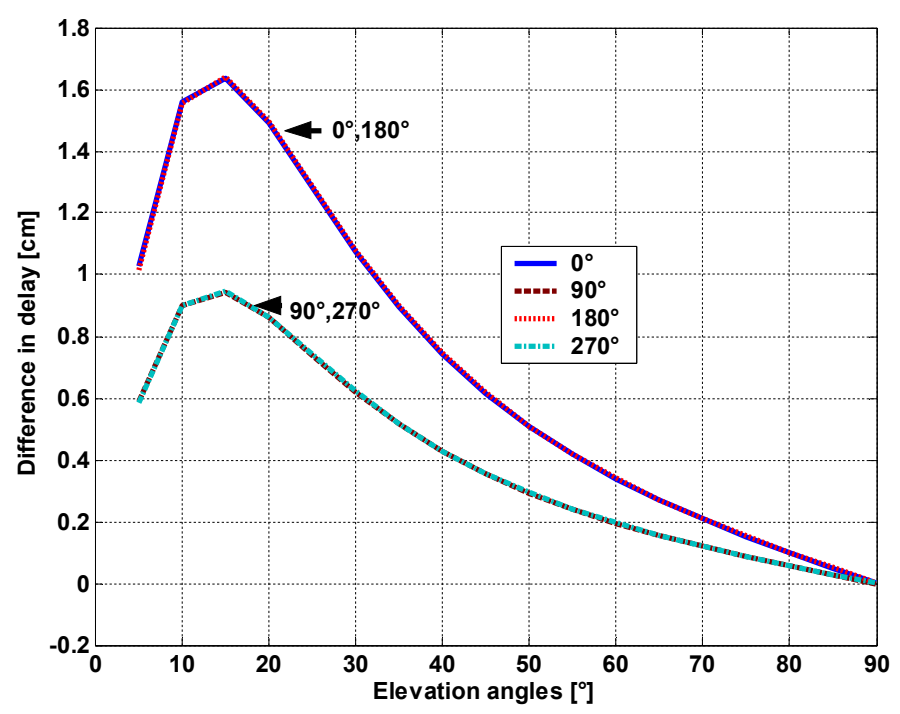

Figure 4. The difference in delay $(\Delta t d)$ between the base station and the four rover stations, with the absolute value of $\Delta t d$ shown for the southern and western orientations. Dash-dot green line, $\Delta t d$ at $270^{\circ}$; dashed brown line, $\Delta t d$ at $90^{\circ}$; dotted red line, $\Delta t d$ at $180^{\circ}$; and solid blue line, $\Delta t d$ at $0^{\circ}$.

\begin{tabular}{rcc} 
Baseline direction & $\begin{array}{c}\text { Ionospheric delay }(\mathbf{c m}) \\
\text { at } 15^{\circ} \text { elevation }\end{array}$ & $\begin{array}{c}\text { Ionospheric delay }(\mathbf{c m}) \\
\text { at } \mathbf{7 0 ^ { \circ }} \text { elevation }\end{array}$ \\
\hline East & 0.9 & 0.1 \\
West & $|-0.9|$ & $|-0.1|$ \\
North & 1.6 & 0.2 \\
South & $|-1.6|$ & $|-0.2|$ \\
\hline
\end{tabular}

Table 1. The ionospheric delay at the four rover stations. rover stations located north and east of the base station, $\Delta t d$ increased as the elevation angle decreased. At elevation angles between $5^{\circ}$ and $15^{\circ}$, the $\Delta t d$ increased rapidly for the north and east orientations. For elevation angles greater than $16^{\circ}$, the $\Delta t d$ decreased gradually, eventually approaching $0 \mathrm{~cm}$ when the elevation angle reached $90^{\circ}$. The similarities between the north and east orientations arose because the propagation path between the stations is almost the same for these two directions. A maximum $\Delta t d$ of $1.6 \mathrm{~cm}$ was measured for the north orientation at $15^{\circ}$ elevation, and $\Delta t d$ decreased to $0.2 \mathrm{~cm}$ at $70^{\circ}$ elevation. In the east direction, $\Delta t d$ had a maximum of $0.9 \mathrm{~cm}$ at $15^{\circ}$ elevation, and decreased to $0.1 \mathrm{~cm}$ at $70^{\circ}$ elevation. The observed decrease in $\Delta t d$ for elevations between $16^{\circ}$ and $89^{\circ}$ is most likely due to decreases in the group delay.

For the rover stations located to the south and west of the base station, $\Delta t d$ had negative values. A graph of the $\Delta t d$ values for these two orientations shows that they were nearly symmetrical to those for the North and East ( $\Delta t d$ for the southern rover station was symmetrical to $\Delta t d$ for the northern station, while $\Delta t d$ for the western station was symmetrical to $\Delta t d$ for the eastern station). The absolute values of $\Delta t d$ for the southern and western orientations are shown in Figure 4. These results imply that relative to the ionospheric delay at the base station, there was a longer delay at the northern and eastern rover stations than at the southern and western stations. Even at these stations, however, the ionospheric delay was greater than that at the base station. Nonetheless, the absolute value of the difference $(\Delta t d)$ at the northern rover station was almost the same as that at the southern station, where $\Delta t d$ reached $-1.6 \mathrm{~cm}$ at $15^{\circ}$ elevation and declined to -0.2 $\mathrm{cm}$ at $70^{\circ}$ elevation. Similarly, the absolute values of $\Delta t d$ were nearly identical at the eastern and western stations, with a $\Delta t d$ of $-0.9 \mathrm{~cm}$ at $15^{\circ}$ elevation and $-0.1 \mathrm{~cm}$ at $70^{\circ}$ elevation. Table 1 summarizes the measured ionospheric delays at the elevation angles of $15^{\circ}$ and $70^{\circ}$ for all four of the station orientations. The small variations in $\Delta t d$ between these different orientations reflect, in part, differences in the satellite-to-receiver paths. However, our results show that the ionosphere is almost equally stratified over the $10-\mathrm{km}$ range studied here.

\section{Conclusions}

The present study has presented the simulations of ionosphere-induced dGPS delays for four different station orientations. The delay difference between the paths to the base station and those to the rover stations has been quantified at an equatorial site. The ionospheric delay difference, $\Delta t d$, is the highest in the northern direction, followed by the eastern direction. The delay measured at the southern station was nearly symmetrical to that measured at the northern station. Similar symmetry was observed for the eastern and western stations. This pattern is the result of differences in the ionospheric delay between the base and rover stations. The delay was larger at the base station than at the northern and 
eastern rover stations, but larger at the southern and western rover stations than at the base station. The absolute values of the differences in delay between the base and the rover stations was nearly identical for symmetrical rover stations. The small observed differences between the different orientations are most likely due to errors along the LOS of each station, which are caused when the satellite signals received at the different stations pass through different regions of the ionosphere. In addition, heterogeneities in the electron content of the ionosphere can lead to different errors for stations at different orientations relative to the satellite-to-receiver paths. This result of the ionospheric errors can be predicted for each rover station using a determined differential delay along the baseline, which provides accurate corrections and more precise positioning.

Acknowledgements. The study reported here was financially supported by the Malaysian Government through the University Kebangsaan Malaysia under the Science Fund grants 04-01-02-SF0191, UKM-KK-01-FRGS0042-2006, UKM-OUP-NBT-28-148/2008 and UKMGUP-NBT-08-28-115. The authors are also grateful to Dr. H.J. Strangeways and Dr. R.T. Ioannides of Leeds University for permission to use part of the ray-tracing program.

\section{References}

Abdullah, M., H.J. Strangeways and D.M.A. Walsh (2003). Accurate ionospheric error correction for differential GPS, In: 12th International Conference on Antennas and Propagation (ICAP 2003; Exeter, UK), 1, 135-138.

Abdullah, M., H.J. Strangeways and D.M.A. Walsh (2007). Effects on ionospheric horizontal gradients on differential GPS, Acta Geophys., 55, 509-523.

Abdullah, M., H.J. Strangeways and D.M.A. Walsh (2008). Extracting ionospheric delay and advance of GPS signals from Appleton-Lassen dispersion equation, In: The 2nd 2007 Asian Physics Symposium (APS 2007), Physic Department, Institut Teknologi Bandung, Indonesia, C20.1C20.7, ISBN 978-979-17090-1-9.

Abdullah, M., H.J. Strangeways and D.M.A. Walsh (2009). Improving ambiguity resolution rate with an accurate ionospheric differential correction, J. Navigation, 62, 151-166.

Abdullah, M., H.J. Strangeways and S.S.N. Zulkifli (2010). Ionospheric differential error determination using ray tracing for a short baseline, Adv. Space Res., 46,1326-1333.

Choy, S., K. Zhang and D. Silcock (2008). An evaluation of various ionospheric error mitigation methods used in single frequency PPP, Journal of Global Positioning Systems, 7, 62-71.

Davies, K. (1990). Ionospheric Radio (IEE Electromagnetic Waves Series, vol. 31), Peter Peregrinus Ltd. on behalf of The Institution of Engineering and Technology, London, 580 pp.

Ioannides, R.T. and H.J. Strangeways (2002). Improved ionospheric correction for dual frequency GPS, In: 27th General Assembly of URSI (Maastricht, the Netherlands, 2002); http: / / www.ursi.org/Proceedings / ProcGA02 / papers / p1874.pdf.

Iyiade, A. (2006). Ionospheric effects on GPS signals in real time kinematic (RTK) applications, In: Position, Location, And Navigation Symposium (IEEE/ION 2006), 1054-1066.

Kintner, P.M. and B.M. Ledvina (2005). The ionosphere, radio navigation, and global navigation satellite systems, Adv. Space Res., 35, 788-811.

Klobuchar, J.A. (1987). Ionospheric time-delay algorithm for single-frequency GPS users, IEEE T. Aero. Elec. Sys., 23, 325-331.

Leitinger, R. and S.M. Radicella (2002). NeQuick ionospheric model; International Telecommunication Union (ITU) official website: http://www.itu.int/publ/R-SOFTSG3/en (accessed April 16, 2010).

Orús, R., M. Hernández-Pajares., J.M. Juan and J. Sanz (2003). Ionospheric Effects on Precise Navigation at Regional and Continental Scales over Europe, In: ISPRS International Workshop on Theory, Technology and Realities of Inertial/GPS Sensor Orientation, 1-8.

Parkinson, B.W. and J.J.J. Spilker, eds. (1996). Global Positioning System: Theory and applications, American Institute of Aeronautics and Astronautics, Washington D.C., USA, vol. I and II.

Strangeways, H.J. (2000). Effect of horizontal gradients on ionospherically reflected or transionospheric paths using a precise homing-in method, J. Atmos. Sol.-Terr. Phy., 62, 1361-1376.

Ya'acob, N., M. Abdullah and M. Ismail (2009). Malaysia precise positioning, Coordinates, 5 (7), July 2009; http: / / mycoordinates.org/malaysia-precise-positioning/.

Zulkifli, S.S.N., M. Abdullah and M. Ismail (2007). Application of 3D Ray-Tracing for Accurate GPS Range Finding, In: The 5th Student Conference on Research and Development (SCOReD; Selangor, Malaysia), 1-5; doi: 10.1109/ SCORED.2007.4451413.

Zulkifli, S.S.N., M. Abdullah, M. Ismail and A.F.M. Zain (2009). Comparison of ionospheric delays between 3D ray-tracing and GPS-TEC measurements, In: International Symposium on GPS/GNSS with the 16th GNSS Workshop (Jeju, Korea, November 4-6, 2009), 1-4.

\footnotetext{
${ }^{\star}$ Corresponding author: Siti Sarah Nik Zulkifli, University Kebangsaan Malaysia, Department of Electrical, Electronic and Systems Engineering; email: sifusara@eng.ukm.my.

C 2011 by the Istituto Nazionale di Geofisica e Vulcanologia. All rights reserved.
} 